\title{
Importance of Legal Expertise for Medical Practitioners in View of Increasing Complexities and Liabilities
}

\author{
Avijit Singh, Nishant Ahlawat \\ Consultant, Paramount Law Consultants Ltd., New Delhi, India
}

Correspondence: Avijit Singh, Project Officer, Paramount Law Consultants Ltd., New Delhi, India, Phone: 9711870085 9990762990, e-mail: info@ paramountlaw.in

\section{ABSTRACT}

A legal duty exists whenever a hospital or health care provider undertakes treatment to a patient. The duty is breached when the provider is failed to conform to the standard care. The breach of duty is a proximate cause of injury. Without damages there is no basis for a claim, regardless of whether the medical provider was negligent. Likewise, damage can occur without negligence, e.g., when someone dies from a fatal disease.

Keywords: Medical malpractice, Medical claim, Medical negligence.

\section{INTRODUCTION}

As the advancement of nanotechnology and data transfer speed reaching to the $3 \mathrm{G}$ and $4 \mathrm{G}$ level so, has shifted the societal situations from simple to complex. Even medical profession and involved rights and liabilities are no exception to it. Before understanding it further, it is important to understand what comes under its purview.

Medicine is the science and art of healing. It encompasses a variety of health care practices evolved to maintain and restore health by the prevention and treatment of illness.

Contemporary medicine applies health science, biomedical research, and medical technology to diagnose and treat injury and disease, typically not only through medication or surgery but also through therapies as diverse as psychotherapy, external splints and traction, prostheses, biologics, ionizing radiation and others. The word medicine is derived from the Latin word 'ars medicina', meaning 'the art of healing'.

Medical malpractice is professional negligence by act or omission by a health care provider in which care provided deviates from accepted standards of practice in the medical community and causes injury or death to the patient with most cases involving medical error. Standards and regulations for medical malpractice vary by country and jurisdiction within countries. Medical professionals may obtain professional liability insurances to offset the risk and costs of lawsuits based on medical malpractice.

A doctor would be liable for (depending on the circumstances) such things as prescribing experimental drugs and performing cosmetic surgery.
There are more than 196 Acts, legislation, rules, regulations and statues, these statues are under interpretation and amendments by the apex court and 21 high courts of India as well as by the various tribunals and statutory authorities on the one hand and the Parliament and state legislators on the other hand. In this background, it really needs an expert to comprehend and imbibe the practical expectations of this chain of statutory regulations from the individual medical practitioner.

Medical profession, these days, is under statutory regulations. And day by day, these regulations are becoming stringent. Individual medical practitioners to super specialty hospitals, there is a big range of medical profession services in practice and accordingly are phased the statutory regulations. These regulations come into play even from the first step of one getting registered as a medical practitioner.

To have a functional hospital services, one is to pass through series of statutory compliances. And to continue these services as well the hospital is to continuously remain under a series of statutory compliances, whose violations may result into punitive implications, which in some situations may even result into imprisonment as well.

Statutory regulations, because of their stringent compliance rules are emerging in the high priority attention, and these being of very technical nature, capable of being attended to by the experts of the discipline, other than that of disciplines of medical knowledge.

Going from generality to specifics, the central focus of concern for the individual medical practitioners are going 
to be as that despite the noble cause being attended by the doctors, the changing norms of the societies are not going by the ancient faith and patience, and instead the day to day fluctuating short-term gains approach of individuals, is bound to eat up the valuable professional time of the doctors to attend nonmedical diversions.

In India's context, its population which is 120 crores, naturally shall be having its gigantic demand from life sciences in practice today. In practical terms, it would reduce to available doctors population with us. The parallel factors, like infrastructure, tools and medicines, certainly are going to be of equal importance but if remained confined to human resource alone, it is to confront us with big posers.

Even the basic formalities as simple as consent form can expose a doctor and medical institutes to heavy liabilities. In United Kingdom and countries, such as Malaysia and Singapore, informed consent requires proof as to the standard of care to be expected as a recognized standard of acceptable professional practice as laid down in Bolam v Friern Hospital Management Committee (1957) 1 WLR 582. Bolam test states that "If a doctor reaches the standard of a responsible body of medical opinion, he is not negligent". Arguably if proved so, this is "sufficient consent" rather than "informed consent".

In the United States, Australia and Canada, a more patient-centered approach is taken and this approach is usually what is meant by the phrase "informed consent". Informed consent in these jurisdictions requires that significant risks be disclosed as well as risks which would be of particular importance to that patient. This approach combines an objective (the reasonable patient) and subjective (this particular patient) approach. The doctrine of informed consent should be contrasted with the general doctrine of medical consent which applies to assault or battery. The consent standard here is that the person understands, in general terms, the nature and purpose of the intended intervention. What is relevant to be mentioned here is that, such small and basic technicalities and their interpretations about basic formalities involved themselves are a gateway to huge liabilities unless they are understood, appreciated and implemented on a case to case basis. As with the advancements in the medical sciences, the peculiarity of the disease, or complications involved and the corresponding treatment or procedure that a patient is subjected to make assessment of such liabilities a prime consideration from all aspects.

\section{MEDICAL MALPRACTICE CLAIMS IN US}

The plaintiff is or was the patient, or a legally designated party acting on behalf of the patient, or-in the case of a wrongful-death suit - the executor or administrator of a deceased patient's estate.
The defendant is the health care provider. Although a 'health care provider' usually refers to a physician, the term includes any medical care provider, including dentists, nurses and therapists. As illustrated in Columbia Medical Center of Las Colinas v Bush, 122 S.W. 3d 835 (Tex. 2003), "following orders" may not protect nurses and other nonphysicians from liability when committing negligent acts. Relying on vicarious liability or direct corporate negligence, which was found in the case of Dany Decell, CEO, claims may also be brought against hospitals, clinics, managed care organizations or medical corporations for the mistakes of their employees.

\section{Elements of the Case}

A plaintiff must establish all four elements of the tort of negligence for a successful medical malpractice claim. ${ }^{1}$

1. The duty was owed: A legal duty exists whenever a hospital or health care provider undertakes care or treatment of a patient.

2. The duty was breached: the provider failed to conform to the relevant standard care.

3. The breach caused an injury: The breach of duty was a proximate cause of the injury.

4. Damages: Without damages (losses which may be pecuniary or emotional), there is no basis for a claim, regardless of whether the medical provider was negligent. Likewise, damages can occur without negligence, e.g., when someone dies from a fatal disease.

\section{Trends in India}

The 1995 apex court judgment holding that the medical profession would fall within the ambit of the Consumer Protection Act and that doctors could be hauled up before consumer courts was opposed tooth and nail by the community. In this era of commercialization, corporate hospitals have been set-up and looked up as high-return institutions in terms of quality as well as revenue. While with advancement of all walks of life, the sacred doctorpatient relationships have also suffered the jolt of the universal factor of mistrust. It may not be out of place to mention that due to unfortunate acts of certain people from the profession, the social pressure has compelled the legislature to further stringent the laws governing the profession. So is the trend with the Medical Council of India, with regard to disciplinary proceedings and punishment meted out to erring doctors. In a recent decision, dealing with the claims of negligence made against the doctors of Batra Hospital ${ }^{2}$, the Supreme Court restated the test for medical negligence. The court examined the previous decisions rendered on the issue to declare the principles regarding negligence as under: 
Firstly, negligence is the breach of a duty exercised by omission to do something which a reasonable man, guided by those considerations which ordinarily regulate the conduct of human affairs, would do, or doing something which a prudent and reasonable man would not do. Secondly, it is an essential ingredient of the offence. The medical professional is expected to bring a reasonable degree of skill and knowledge and must exercise a reasonable degree of care. Neither the highest nor a very low degree of care and competence judged in the light of the particular circumstances of each case is what the law requires. Also a medical practitioner would be liable only where his conduct fell below that of the standards of a reasonably competent practitioner in his field. In the realm of diagnosis and treatment there is scope for genuine difference of opinion and one professional doctor is clearly not negligent merely because his conclusion differs from that of other professional doctor. The medical professional is often called upon to adopt a procedure which involves higher element of risk, but which he honestly believes, is providing greater chances of success for the patient rather than a procedure involving lesser risk but higher chances of failure. Just because a professional looking to the gravity of illness has taken higher element of risk to redeem the patient out of his/her suffering which did not yield the desired result may not amount to negligence.

Unlike personal laws dealing with marriage, divorce and inheritance, the criminal law of the land makes no distinction on grounds of religion, caste, class or profession. Section 304-A of the Indian Penal Code titled causing death by negligence lays down that whoever causes the death of any person by doing any rash or negligent act not amounting to culpable homicide, shall be punished with imprisonment of either description for a term which may extend to 2 years or with fine, or both.

Similarly, sections of the Penal Code pertaining to grievous hurt, culpable homicide or murder are uniformly applicable. The only provision which protects a doctor from a charge of grievous hurt in case of surgical interventions and culpable homicide in case of the death of the patient on the operating table is Section 88 of the Penal Code. However, the protection is available only if the act is done in good faith.

Chemical based present day medicines and plant based and like ancient systems have divergent approaches. The economics and business attached with them as well are playing their role for the applied values and welfare of health prospective concerns of different sections of population being at their receiving end. This as such focuses upon the need for a fresh look for comprehensive integrated systems for medical education and practices. Wide spectrum of population distribution on the basis of illiteracy, health literacy, particular system literates, experts, specialists and all that while interacting amongst themselves are bound to cause stress and strain and heat, which is to be systemically absorbed to avoid distortions for the natural features of existence phenomenon. Compliance issues, litigations and all that are the outcome of such strains and heat, among others, adversely affecting the prime time of the medical professionals, shall be causing repercussion spirals, which ultimately are bound to prove suicidal for the ideal of healthy life span services values.

These issues, infact are nonmedical issues, in the sense that these as such are to be handled outside the domain of life sciences. Nevertheless, these issues, as such because of their consequences, have become institutional governance concerns of collective existence management systems of the democratic society.

Parallel to the medical issues, these legal issues as well are evolving in their research strategies, modalities and approach. Illustratively, the man-machine integration laboratories and colonization of other planets as future home of man. The success of having zero gravity crops, test tube meat and the like are bound to bring in parallel legal issues to be handled by legal experts for medical professionals.

Placing it further, it is the changing need of the society that legal immunity be strengthened instead of waiting for the doomsday, when the sacred profession is discussed in the courts of law. The advancements in stem cell based research, such as well human cloning and other such scientific possibilities, are countered with their legalities, which if not dealt with, can halt the prime focus of such developments, i.e. serving the mankind. Analyzing it with the complexities of laws involved, for which keeping absolutely updated with the same is not a practical approach for any medical practitioner. However, it is high time that there should be the right nature and orientation of legal navigation available for every such professional in order to minimize the chances of any possible legal friction thus resultantly enhancing and strengthening the legal immunity of every individual and professional involved in such a noble dedication to the mankind and humane.

Normally, a doctor can never expect to be exposed to such professional liabilities, its a thought that it cannot be happened to him, and does not wish to believe that he can be implicated in such cases, or either that he/she is too young and new to fall for it or he is too mature and responsible for facing any such situations.

When a doctor faces such a situation, the first thing that will come to his/her mind is "my career is over,/I have been careful,/I know that I did not do anything wrong".

What follows is a social and professional stigma as what dominates this noble profession is the trust and goodwill, and once it is shattered then the damage cannot be assessed 
in terms of any value. The consequences take a heavy toll on the professional practice of doctor. After learning about the lawsuit, you would not be able to practice like you would like to, you would not be able to focus on patients like you should, and then a continuous tickling thought is how and what would your coworkers think about you.

We are fully conscious of the values of the prime time and dignity of the medical professional and virtues of the life saving efforts of dedicated doctors/hospitals for the cause. It is an expert research-based approach, legal consultancy and litigation management, which is going to be of much practical help for all those in the profession who want to be blissfully sure about their statutory compliances and want to be free from any tension on that front so that they may fully remain concentrated about their highly valuable medical services.
It is in this background that we encourage you to subscribe to a legal consultancy service and litigation management mechanism crafted specially for medical practitioners.

\section{ACKNOWLEDGMENT}

Indolegals

Legal Consultancy and Litigation Management Services www.indolegals.com

info@indolegals.com

\section{REFERENCES}

1. The four elements of medical malpractice. Yale New Haven Medical Center: Issues in Risk Management 1997.

2. Kusum Sharma and others versus Batra Hospital and Medical Research Center and others (Civil Appeal 1385 of 2001). 